\title{
Regulation of amylase gene expression in diabetic mice is mediated by a cis-acting upstream element close to the pancreas- specific enhancer
}

\author{
Scott A. Keller, Michael P. Rosenberg, ${ }^{1}$ Thomas M. Johnson, Georgette Howard, \\ and Miriam H. Meisler \\ Department of Human Genetics, University of Michigan, Ann Arbor, Michigan 48109-0618 USA; ${ }^{1}$ Department of Molecular \\ Biology, Squibb Institute for Medical Research, Princeton, New Jersey 08543 USA
}

\begin{abstract}
We localized the cis-acting sequences that mediate the regulation of a pancreatic amylase gene, Amy-2.2, in diabetic mice. We constructed three hybrid genes containing sequences from the 5 '-flanking region of the amylase gene upstream of the heterologous elastase promoter linked to the CAT structural gene. These constructs were transferred to the germ line of transgenic mice by microinjection of fertilized eggs. The amylase sequences had two effects on expression of the elastase promoter: Basal expression was increased, and expression in diabetic animals was reduced to $\sim 2 \%$ of basal levels. A 30 -bp amylase fragment was sufficient to transfer both of these regulatory functions to the elastase promoter. Sequences within this 30-bp fragment are included in the binding site for the pancreatic nuclear protein PTF1. The close association of the PTF1-binding site and the regulatory functions is consistent with a mechanism based on interference with activation by PTF1 in diabetic pancreas. PTF1-binding activity is not reduced in diabetic pancreas. The data presented here demonstrate that the 5 '-flanking region of the pancreatic amylase gene contains a novel insulin-dependent element (IDE) that mediates the loss of expression in diabetic animals.
\end{abstract}

[Key Words: Amylase; diabetes; insulin; pancreas; transgenic mice]

Received March 19, 1990; revised version accepted May 29, 1990.

Amylase mRNA is the most abundant message in pancreatic acinar cells, accounting for $\sim 20 \%$ of pancreatic mRNA (Schibler et al. 1980). It has been known for many years that the synthesis of amylase is dramatically reduced in pancreas of diabetic rodents (Ben-Abdeljlil et al. 1965; Palla et al. 1968). Pancreatic amylase can subsequently be induced to its normal level by administration of insulin to the diabetic animals. Expression of pancreatic amylase thus appears to be insulin-dependent. Korc et al. (1981) demonstrated that the amylase mRNA is reduced in pancreas of diabetic animals and restored by treatment with insulin. The 100 -fold increase of amylase mRNA obtained by treatment of diabetic animals with insulin is one of the largest effects of insulin on a specific mRNA (for review, see Meisler and Howard 1989). The response to insulin is retained in a chloramphenicol acetyltransferase (CAT) construct containing only $227 \mathrm{bp}$ of sequence $(-208 /+19)$ from the mouse pancreatic amylase gene Amy-2.2 (Osborn et al. 1988).

Amylase is the only pancreas-specific gene whose expression is known to be reduced in diabetic pancreas. Elastase, trypsin, chymotrypsin, lipase, and ribonuclease are also expressed specifically in pancreas but are not affected in diabetic animals (Palla et al. 1968; Söling and Unger 1972; Korc et al. 1981; L.C. Samuelson and M.H. Meisler, unpubl.). Regulation by insulin is thus amylase-specific and is probably related to the unique role of amylase in carbohydrate metabolism.

The molecular basis for pancreas-specific expression of amylase and other digestive enzymes has recently been clarified by the identification of a pancreatic nuclear protein, PTF1, that binds to a conserved cis-acting element in the $5^{\prime}$-flanking region of several pancreasspecific genes, including amylase, trypsin, elastase, and chymotrypsin (Cockell et al. 1989; Howard et al. 1989; Meister et al. 1989; Roux et al. 1989). The conserved DNA element has enhancer activity in cultured pancreatic cells (Boulet et al. 1986; Kruse et al. 1988). Site-directed mutations of this element that eliminate PTF1 binding also eliminate enhancer activity (Howard et al. 1989). In transgenic mice, a 134-bp fragment from the 5 '-flanking region of the elastase I gene, which contains the enhancer element, is sufficient to direct pancreasspecific expression of a heterologous promoter (Hammer et al. 1987). These studies indicate that PTF1 plays a key role in activation of genes in the acinar cells of the pancreas. 
1.

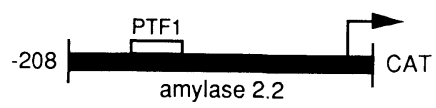

2.
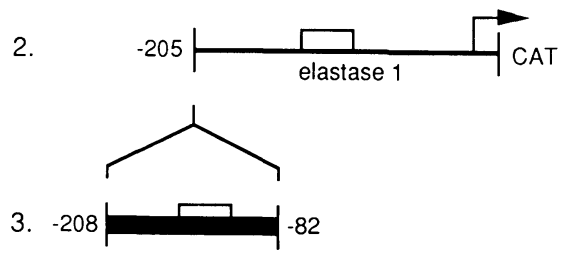

4. 110

5. -167 -138

Figure 1. Structure of hybrid genes transferred to transgenic mice. Open rectangles represent binding sites for the pancreatic nuclear protein PTF1 (Cockell et al. 1989; Howard et al. 1989).

Previously, we localized a PTF1-binding site to the region -158 to -122 of the mouse Amy-2.2 gene promoter (Howard et al. 1989). The present study was undertaken to localize the insulin-dependent element of the gene. Our results demonstrate that the response to insulin is mediated by sequences close to or overlapping the PTF1-binding site.

\section{Results}

\section{Hybrid genes}

The structures of the five hybrid genes that have been studied are represented in Figure 1. The amylase $(-208 /$ +19 / CAT hybrid gene (construct 1) was shown previously to be regulated by insulin in pancreas of transgenic mice (Osborn et al. 1988). The elastase (-205/ +22 )/CAT construct (construct 2) is expressed in cultured acinar cells (Kruse et al. 1988; Swift et al. 1989) but has not been studied previously in transgenic mice. The same elastase promoter fragment directed pancreasspecific expression of the growth hormone gene in transgenic mice (Ornitz et al. 1985a,b). To localize the insulin-responsive element in construct 1 , three subfragments were subcloned upstream of the elastase promoter to generate constructs $3-5$. The elastase promoter and each of the amylase fragments contain PTF1binding sites (open rectangles). The ability of the partial site in construct 5 to bind PTF1 was confirmed with a gel mobility-shift assay (T.M. Johnson, unpubl.).

\section{Expression of amylase/elastase/CAT constructs in pancreas of transgenic mice}

Transgenic mice were generated by microinjection of 2-kb restriction fragments containing each of the hybrid constructs. Founder animals were identified by detection of CAT sequences in genomic DNA by use of Southern blots or polymerase chain reaction (PCR). Founders were crossed to strain C57BL/6J to generate transgenic lines, which were maintained by continued backcrossing to this strain. The transgenes were transmitted to $50 \%$ of offspring by autosomal inheritance.

Pancreatic CAT activity of 17 transgenic lines carrying the hybrid genes is summarized in Figure 2. Four of the six independent transgenic lines with the elastase/ CAT hybrid (construct 2) did not contain detectable CAT activity in pancreas; the remaining lines contained a low level of pancreatic CAT (Fig. 2). Addition of the amylase fragments to construct 2 resulted in significantly higher levels of pancreatic CAT (Fig. 2, constructs $3-5$ ). The amylase fragments thus appear to act as enhancers in vivo. Enhancer activity was observed previously in transfected cells for constructs 3 and 4 . The enhancer activity was dependent on PTFl, because mutations that eliminate binding also eliminate enhancer activity (Howard et al. 1989).

The quantitative level of expression in the transgenic lines was not correlated with copy number, which varied from 1 to 50 copies in different lines.

\section{Reduced expression in diabetic mice}

To evaluate insulin dependence, transgenic mice were treated with the $\beta$-cell toxin streptozotocin to induce insulin deficiency. Residual CAT activity was measured in homogenates of pancreas from hyperglycemic diabetic animals with blood glucose levels $>400 \mathrm{mg} / \mathrm{dl}$. To control for effects of the streptozotocin treatment on the CAT reporter, we tested mice carrying a Rous sarcoma virus-CAT (RSV/CAT) construct (Overbeek et al. 1986). To control for the response of the elastase promoter alone, we examined the effect of streptozotocin on transgenic mice with the elastase-CAT gene (construct 2). For both of these controls, the residual CAT

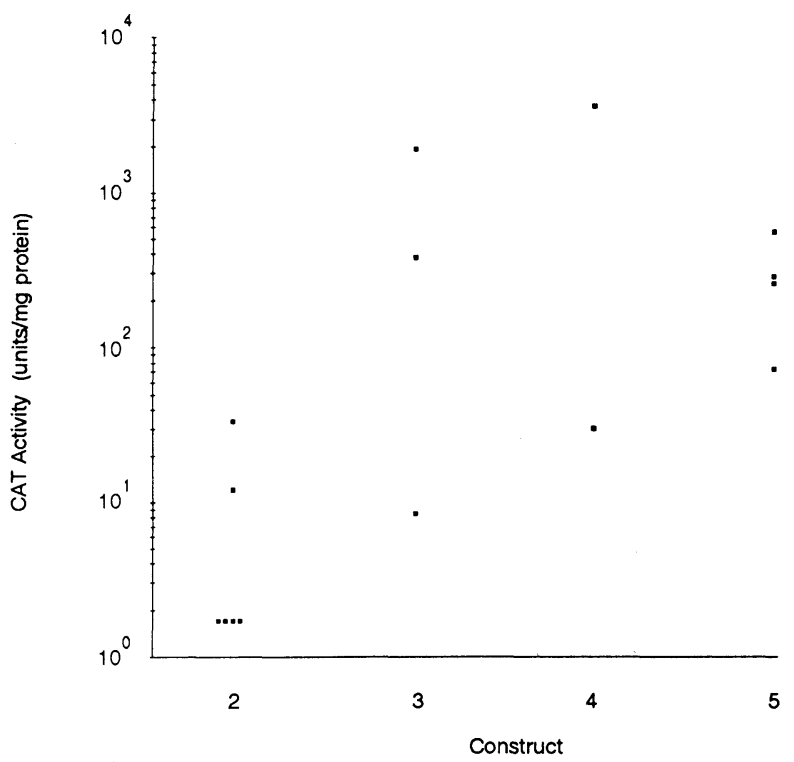

Figure 2. Expression of hybrid genes in 17 independent transgenic lines. The structures of constructs $1-5$ are presented in Fig. 1. CAT activity in pancreas was assayed as described in Methods. Each point represents the mean pancreatic CAT activity for a single transgenic line. 
Table 1. Effect of streptozotocin on pancreatic CAT activity in transgenic mice

\begin{tabular}{|c|c|c|c|c|c|c|c|}
\hline \multirow{2}{*}{$\begin{array}{l}\text { Transgenic } \\
\text { line }\end{array}$} & \multirow[b]{2}{*}{ Construct } & \multirow{2}{*}{$\begin{array}{l}\text { Amylase } \\
\text { sequences }\end{array}$} & \multicolumn{4}{|c|}{ Pancreatic CAT (U/mg protein) } & \multirow{2}{*}{$\begin{array}{l}\text { Residual } \\
\text { activity (\%) }\end{array}$} \\
\hline & & & untreated & & diabetic & & \\
\hline RSV/CAT & & - & $150 \pm 28$ & (5) & $79 \pm 38$ & (6) & 53 \\
\hline 885 & 2 & - & $33 \pm 3.1$ & (4) & $15 \pm 6.5$ & (9) & 45 \\
\hline 6223 & 3 & + & $380 \pm 62$ & (4) & $5.3 \pm 1.6$ & (4) & 1.4 \\
\hline 6208 & 3 & + & $1900 \pm 970$ & (2) & 29 & (1) & 1.5 \\
\hline 5428 & 4 & + & $3600 \pm 1500$ & (4) & $6.4 \pm 2.1$ & (4) & 0.2 \\
\hline 5440 & 4 & + & $29 \pm 13$ & (5) & $0.2 \pm 0.1$ & (3) & 0.7 \\
\hline 6866 & 5 & + & $7400 \pm 1400$ & (4) & $190 \pm 120$ & (2) & 2.6 \\
\hline 261 & 5 & + & $1900 \pm 540$ & (5) & $22 \pm 14$ & (3) & 1.2 \\
\hline
\end{tabular}

The structures of the transferred constructs are presented in Fig. 1. Pancreatic homogenates from transgenic mice were assayed as described in Methods. All data were obtained from the linear range of the CAT assay. Values are mean $\pm \operatorname{SE}(n)$ or mean \pm range when $n=2$.

activity in treated mice was $\sim 50 \%$ of normal values (Table 1).

The effect of the amylase fragments on the response of the elastase promoter is presented in Table 1. Expression of constructs 3-5 was dramatically reduced by the streptozotocin treatment. Two independent transgenic lines were tested for each construct. In all of the lines, CAT activity was reduced to $<3 \%$ of starting activity. The response of the hybrid genes is comparable in magnitude to that of the intact Amy-2.2 gene (Osborn et al. 1987,1988 ), indicating that each of the transferred amylase fragments contains the functional regulatory element.

\section{Lack of regulation by insulin in stomach}

Recently we observed that the Amy- 2.2 promoter is expressed in stomach, at a level $\sim 0.05 \%$ of pancreatic expression (Ceci et al., in prep.). To determine whether the expression in stomach is repressed in diabetic mice, we analyzed the effect of streptozotocin on mice carrying the amylase-CAT hybrid gene (construct 1). In these animals, CAT activity in pancreas was reduced to $<1 \%$ of the untreated controls (Table 2); however, in the same animals there was no reduction in the CAT activity in stomach (Table 2). CAT activity was not detected in other tissues of these mice.

Normal levels of the pancreas-specific enhancerbinding protein PTF1 in diabetic pancreas

The amylase fragments in the regulated constructs contain functional PTF1-binding sites. To test the possibility that PTF1 from diabetic pancreas is reduced in capacity to bind the amylase enhancer, we compared PTF1 activity from normal and diabetic animals. PTFl was partially purified from nuclear extracts by ion exchange chromatography. Binding activity of the purified fractions was compared in a gel mobility-shift assay by use of the radiolabeled Amy-2.2 fragment -172/-110, as described previously (Howard et al. 1989). We observed comparable levels of PTF1-binding activity in $0.4 \mu \mathrm{g}$ of protein purified from normal and diabetic pancreas (Fig. 3 ). The mobility of the complexes was also the same in the two preparations. These observations indicate that reduced PTF1 binding activity is unlikely to account for the reduced expression of amylase in diabetic pancreas.

\section{Discussion}

In diabetic rodents, the synthesis of pancreatic amylase is reduced by two orders of magnitude from the normal level. This effect can be produced by treatment with a variety of diabetogenic agents, including streptozotocin, alloxan, and diazamide (Söling and Unger 1972). The ability of insulin to restore normal levels in diabetic animals has been established for the intact amylase gene (Ben-Abdeljlil et al. 1965; Palla et al. 1968; Korc et al. 1981; Osborn et al. 1987) and for an amylase (-208/ +19 )/CAT hybrid gene (Osborn et al. 1988). The use of transgenic mice enabled us to study this regulatory function of insulin, for which a cultured cell model is not available.

There was considerable variation in the amount of pancreatic CAT produced by different transgenic lines with the same hybrid construct. This observation suggests that our constructs do not contain the type of element that produces site-independent expression of globin genes in transgenic mice (Talbot et al. 1989). If such an element exists for pancreas-specific genes, it must be located outside of the small promoter fragments in our constructs. The differences in constitutive levels of expression among the transgenic lines did not influence the regulatory response.

After treatment of transgenic mice with streptozo-

Table 2. Expression of the Amy-2.2 promoter in stomach is not subject to negative regulation

\begin{tabular}{lcc}
\hline & \multicolumn{2}{c}{ CAT (U/mg protein) } \\
\cline { 2 - 3 } Tissue & untreated & diabetic \\
& $(n=7)$ & $57 \pm 23$ \\
\hline Pancreas & $7400 \pm 1500$ & $9.1 \pm 0.7$ \\
Stomach & $6.0 \pm 0.8$ &
\end{tabular}

Stomach and pancreas were isolated from the same individuals of transgenic line 6833 carrying Amy-2.2 (-208 to + 19)/CAT (construct 1, Fig. 2). Both tissues were analyzed for CAT activity, as described in Methods and Table 1. 


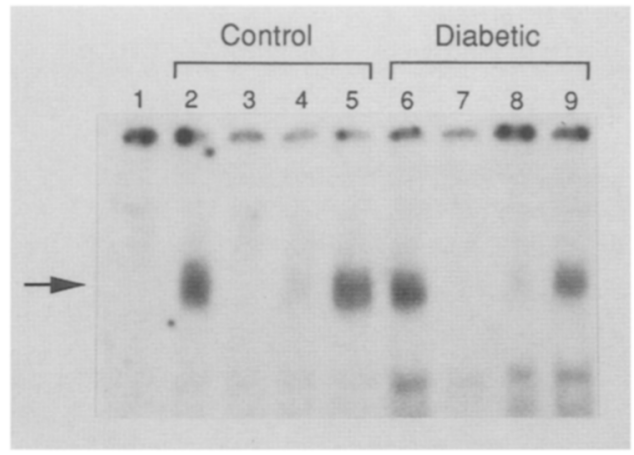

Figure 3. Diabetic pancreas is not deficient in the enhancerbinding protein PTF1. PTF1 was partially purified from pancreatic nuclear protein as described in Methods. Protein (400-ng aliquots) from normal or diabetic animals was incubated with the radiolabeled 62-bp amylase probe $(-172 /-110)$. Unlabeled competitor DNAs were present at 500 -fold molar excess. (Lane 1) Probe alone; (lanes 2 and 6) no competitor; (lanes 3 and 7) competition by unlabeled probe; (lanes 4 and 8 ) competition by elastase I enhancer $(-122 /-92)$; (lanes 5 and 9) competition by an unrelated fragment of pBR322.

tocin, we observed a 50 - to 100 -fold reduction in expression of all of the constructs containing amylase sequences. In contrast, the expression of the elastase/CAT construct without amylase sequences was reduced only twofold, as was the RSV/CAT control. The dramatically reduced expression in diabetic pancreas is therefore an effect of the amylase sequences. The results demonstrate that a nontranscribed sequence, designated the insulin dependent element (IDE), is sufficient to confer insulin-dependent expression on a heterologous promoter. The IDE has been localized to a 30-bp region of Amy-2.2: - 167 CAGTTTATTT TGCGTGAGAG TTTCTAAAA -138 .

The underlined nucleotides are protected from nuclease digestion by binding of the pancreatic nuclear factor PTF1 (Howard et al. 1989). The close association of the IDE and the binding site for PTF1 suggests that interference with the normal function of PTFl is likely to be involved in reduced amylase expression in diabetic pancreas. Mutations that prevent binding of PTF1 are known to reduce the activity of the amylase enhancer (Howard et al. 1989); however, data presented here demonstrate that diabetic pancreas is not deficient in PTF1. Complete loss of PTF1 could not account for the observations, in any case, because the regulation is specific to amylase and does not affect other genes that bind PTF1, such as elastase and chymotrypsin.

Several mechanisms can be considered to account for a PTF1-mediated effect that is specific to the Amy-2.2 gene. Binding of a repressor to amylase-specific sequences within the IDE, adjacent to or overlapping the PTF1 site, might prevent activation by PTF1. The function of insulin in this model would be to maintain the repressor in an inactive state. Experiments designed to detect a repressor in diabetic pancreas with affinity for the IDE have thus far been unsuccessful. In an alternative model, modification of PTF1, itself, or of an accessory protein might specifically prevent activation of the amylase gene without affecting expression of elastase or chymotrypsin. Isolation and characterization of the regulatory proteins from normal and diabetic pancreas will be required to test this model.

The expression of one amylase/CAT hybrid gene /construct 1) was examined in stomach tissue. In diabetic animals, expression was not reduced in stomach, whereas expression in pancreas of the same animals was greatly reduced. The lack of regulation in stomach provides additional evidence that pancreas-specific factors may be required.

Insulin is known to induce transcription of the c-fos gene via binding of a nuclear protein, the serum response factor, to a 15-nucleotide serum response element (Norman et al. 1988; Stumpo et al. 1988). The Amy-2.2 gene contains an 11-nucleotide direct repeat that is similar in sequence to the serum response element of c-fos at 8 of 11 nucleotides (Osborn et al. 1988). Because this direct repeat is not contained within the IDE, it is evidently not required for regulation by insulin; however, its location adjacent to the IDE suggests that this element could influence regulation of the intact gene.

Amylase catalyzes the first step in catabolism of starch to glucose, and amylase expression is repressed in many organisms when high levels of glucose are present. For example, transcription of bacterial amylase is regulated by the catabolite repression mechanism (Nicholson et al. 1987), and amylase can be repressed in Drosophila by feeding a diet high in glucose (Benkel and Hickey 1986). Because the diabetic state in mammals is characterized by elevated concentrations of circulating glucose, it may be analogous physiologically to conditions of glucose abundance in lower organisms. Comparison of the molecular mechanisms for regulation of amylase in these three organisms will provide an interesting example of evolution of a regulatory function.

\section{Methods \\ Construction of hybrid genes}

Plasmid pE1mCAT containing construct 2 (Fig. 1) was the generous gift of R. MacDonald (Kruse et al. 1988). Restriction fragments were isolated from the Amy-2.2 promoter and inserted into the polylinker of $\mathrm{pE} 1 \mathrm{mCAT}$ to generate constructs 3 and 4, as described previously (Howard et al. 1989). Complementary oligonucleotides corresponding to the amylase fragment in construct 5 were synthesized: coding strand, 5'-GATCCAGTTTATTTTGCGTGAGAGTTTCTAAAA-3'; noncoding strand, 5' GGACTTTTAGAAACTCTCACGCAAAATAAACTG-3'. The oligonucleotides were annealed and incubated with deoxynucleotide triphosphates and DNA polymerase Klenow fragment. After digestion with S1 nuclease, the blunt-ended double-stranded fragments were ligated to linearized $\mathrm{pE} 1 \mathrm{mCAT}$ plasmid DNA. The plasmid DNA was prepared by digestion with PstI, followed by treatment with S1 nuclease. The sequences of the resulting constructs were confirmed by doublestranded dideoxynucleotide sequencing. 


\section{Transgenic animals}

Plasmid DNAs were digested with HindIII and SacI. Two-kilobase restriction fragments containing the hybrid genes were purified from agarose gels and microinjected into fertilized mouse eggs by the methods described previously (Osborn et al. 1987). Genomic DNA was prepared and analyzed on Southern blots by hybridization with a probe from the CAT structural gene (Osborn et al. 1988).

Transgenic line 6833 was generated by microinjection of a recloned construct 1 to eliminate the out-of-frame AUG in the original lines (L.C. Samuelson, pers. comm.). Transgenic mice carrying two copies of an RSV-CAT fusion gene (Overbeek et al. 1986, strain 3) were obtained from Dr. Paul Overbeek, Baylor College of Medicine.

\section{Amplification of CAT sequences with PCR}

The two 30-bp primers corresponded to the CAT-coding strand $(+4868)$ CCAGACCGTTCAGCTGGATATTACGGCCTT $(+4839)$ and noncoding strand $(+4625)$ CTGCCGGAAATCGTCGTGGTATTCACTCCA (+4654) (Gorman 1985). Amplification reactions containing $0.5-1.0 \mu \mathrm{g}$ of genomic DNA and 1 unit of Taq polymerase (Perkin-Elmer Cetus) were incubated under standard conditions for 24 cycles of $75 \mathrm{sec}$ at $94^{\circ} \mathrm{C}$, alternating with $3 \mathrm{~min}$ at $72^{\circ} \mathrm{C}$, in a programmable thermal controller model PTC-100 (MJ Research, Inc., Boston, MA). The 244-bp amplified product was detected by electrophoresis through $6 \%$ nondenaturing polyacrylamide gel, followed by staining with ethidium bromide.

\section{Streptozotocin treatment}

Streptozotocin was administered by intraperitoneal injection, and diabetes was monitored by measurement of urinary glucose, as described previously (Osborn et al. 1987, 1988). At the time of sacrifice, blood glucose levels were determined with a Johnson and Johnson glucose meter. Animals with blood glucose $>400 \mathrm{mg} / \mathrm{dl}$ were included in the study.

\section{CAT assays}

Homogenates of pancreas and stomach were assayed as described previously (Osborn et al. 1988). One unit of CAT acetylates $1 \%$ of substrate per hour under standard conditions: incubation for $3 \mathrm{hr}$ at $37^{\circ} \mathrm{C}$ in $0.25 \mathrm{M}$ Tris $(\mathrm{pH} 7.8)$ with $0.2 \mu \mathrm{Ci}$ $\left[{ }^{14} \mathrm{C}\right]$-chloramphenicol and $2.2 \mathrm{mg} / \mathrm{ml}$ acetyl CoA, in a total volume of $150 \mu \mathrm{l}$. Reactions contained sufficient protein to acetylate $1-50 \%$ of substrate; the assay was linear within this range. Experimental data were corrected by subtraction of background radioactivity due to impurities in the substrate that comigrated with product on TLC plates. Background was measured for each experiment and was $\sim 0.3 \%$ of total $\mathrm{cpm}$, or 500 cpm per assay.

\section{PTF1-binding assay}

The assay of PTF1 with a ${ }^{32}$ P-labeled Amy-2.2 fragment (-172/ -110 ) was described previously (Howard et al. 1989). PTF1 binding to the amylase fragment is competed by the corresponding enhancer sequence from the rat elastase 1 gene (nucleotides -122 to -92 ); the unrelated pBR322 fragment +3728 to +3846 does not compete. Nuclear extracts from normal and diabetic pancreas were fractionated by chromatography on BioRex 70 and elution with $0.3-0.4 \mathrm{M} \mathrm{KCl}$ as described previously (Howard et al. 1989).

\section{Acknowledgments}

We thank Julie M. Jones for expert technical assistance, Deborah Swing (National Cancer Institute, Frederick) for assistance in production of transgenic mice, and Dr. Laurelee Osborn for helpful discussions during the early stages of the project. We are grateful to Dr. Raymond MacDonald for the gift of plasmid pE1-mCAT and to Dr. Paul Overbeek for providing transgenic mice with the RSV/CAT fusion gene. This work was supported by U.S. Public Health Service grants GM-24872 and DK-36089. S.A.K. acknowledges support from the Graduate Program in Cellular and Molecular Biology (GM-07315). G.H. was supported by National Research Service Award DK-08137. T.M.J. was the recipient of support from the Thurnau Fund and the Rackham School of Graduate Studies at the University of Michigan.

The publication costs of this article were defrayed in part by payment of page charges. This article must therefore be marked "advertisement" in accordance with 18 USC section 1734 solely to indicate this fact.

\section{References}

Ben Abdeljlil, A., J.C. Palla, and P. Desnuelle. 1965. Effect of insulin on pancreatic amylase and chymotrypsinogen. Biochem. Biophys. Res. Commun. 18: 71-75.

Benkel, B.F. and D.A. Hickey. 1986. Glucose repression of amylase gene expression in Drosophila melanogaster. Genetics 114: 137-144.

Boulet, A.M., C.R. Erwin and W.J. Rutter. 1986. Cell-specific enhancers in the rat exocrine pancreas. Proc. Natl. Acad. Sci. 83: 3599-3603.

Cockell, M., B.J. Stevenson, M. Strubin, O. Hagenbüchle, and P.K. Wellauer. 1989. Identification of a cell-specific DNAbinding activity that interacts with a transcriptional activator of genes expressed in the acinar pancreas. Mol. Cell. Biol. 9: 2464-2476.

Gorman, C.M. 1985. High efficiency gene transfer into mammalian cells. In DNA cloning (ed. D. Glover), IRL Press Limited, Oxford.

Hammer, R.E., G.H. Swift, D.M. Ornitz, C.J. Quaife, R.D. Palmiter, R.L. Brinster, and R.J. MacDonald. 1987. The rat elastase I regulatory element is an enhancer that directs correct cell-specificity and developmental onset of expression in transgenic mice. Mol. Cell. Biol. 7: 2956-2967.

Howard, G., P.R. Keller, T.M. Johnson, and M.H. Meisler. 1989. Binding of a pancreatic nuclear protein is correlated with amylase enhancer activity. Nucleic Acids Res. 17: 81858195.

Korc, M., D. Owerbach, C. Quinto, and W.J. Rutter. 1981. Pancreatic islet acinar cell interaction: Amylase messenger RNA levels are determined by insulin. Science 213: 351353.

Kruse, F., C.T. Komro, C.J. Michnoff, and R.J. MacDonald. 1988. The cell-specific elastase I enhancer comprises two domains. Mol. Cell. Biol. 8: 893-902.

Meisler, M.H. and G. Howard. 1989. Effects of insulin on gene transcription. Annu. Rev. Physiol. 51: 701-714.

Meister, A., S.L. Weinrich, C. Nelson, and W.J. Rutter. 1989. The chymotrypsin enhancer core. Specific factor binding and biological activity. J. Biol. Chem. 264: 20744-20751.

Nicholson, W.L., Y.-K. Park, T.M. Henkin, M. Won, M.J. Weickert, J.A. Gaskell, and G.H. Chambliss. 1987. Catabolite repression-resistant mutations of the Bacillus subtilis alpha-amylase promoter affect transcription levels and are in an operator-like sequence. J. Mol. Biol. 198: 609-618. 
Norman, C., M. Runswick, R. Pollock, and R. Treisman. 1988. Isolation and properties of cDNA clones encoding SRF, a transcription factor that binds to the $\mathrm{c}$-fos serum response element. Cell 55: 989-1003.

Ornitz, D.M., R.D. Palmiter, R.E. Hammer, R.L. Brinster, G.H. Swift, and R.J. MacDonald. 1985a. Specific expression of an elastase-human growth hormone fusion gene in pancreatic acinar cells of transgenic mice. Nature 313: 600-602.

Ornitz, D.M., R.D. Palmiter, A. Messing, R.E. Hammer, C.A. Pinkert, and R.L. Brinster. 1985b. Elastase I promoter directs expression of human growth hormone and SV40 T antigen genes to pancreatic acinar cells in transgenic mice. Cold Spring Harbor Symp. Quant. Biol. 50: 399-409.

Osborn, L., M.P. Rosenberg, S.A. Keller, and M.H Meisler. 1987. Tissue specific and insulin-dependent expre ssion of a pancreatic amylase gene in transgenic mice. Mol. Cell. Biol. 7: 326-334.

Osborn, L., M.P. Rosenberg, S.A. Keller, C.-N. Ting, and M.H. Meisler. 1988. Insulin response of a hybrid amylase/CAT gene in transgenic mice. J. Biol. Chem. 263: 16519-16522.

Overbeek, P.A., S.-P. Lai, K.R. Van Quill, and H. Westphal. 1986. Tissue-specific expression in transgenic mice of a fused gene containing RSV terminal sequences. Science 231: 1574-1577.

Palla, J.-C., A. Ben Abdeljlil, and P. Desnuelle. 1968. Action de l'insuline sur la biosynthesse de l'amylase et de quelques autres enzymes du pancreas de rat. Biochim. Biophys. Acta 158: $25-35$.

Roux, E., M. Strubin, O. Hagenbüchle, and P.K. Wellauer. 1989. The cell-specific transcription factor PTF1 contains two different subunits that interact with the DNA. Genes Dev. 3: $1613-1624$.

Schibler, U., M. Tosi, A.-C. Pittet, L. Fabiani, and P.K. Wellauer. 1980. Tissue-specific expression of mouse alpha-amylase genes. J. Mol. Biol. 142: 93-116.

Söling, H.D. and K.O. Unger. 1972. The role of insulin in the regulation of alpha-amylase synthesis in the rat pancreas. Eur. J. Clin. Invest. 2: 199-212.

Stumpo, D.J., T.N. Stewart, M.Z. Gilman, and P.J. Blackshear. 1988. Identification of $c$-fos sequences involved in induction by insulin and phorbol esters. I. Biol. Chem. 263: 16111614.

Swift, G.H., F. Kruse, R.J. MacDonald, and R.E. Hammer. 1989. Differential requirements for cell-specific elastase I enhancer domains in transfected cells and transgenic mice. Genes Dev. 3: 687-696.

Talbot, D., P. Collis, M. Antoniou, M. Vidal, F. Grosveld, and D.R. Greaves. 1989. A dominant control region from the human beta-globin locus conferring integration site-independent gene expression. Nature 338: 352-355. 


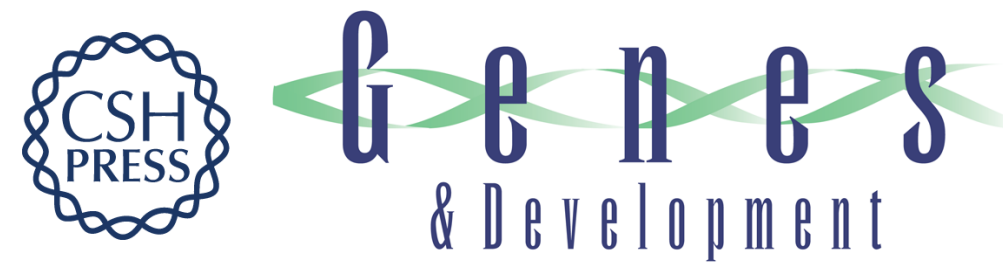

\section{Regulation of amylase gene expression in diabetic mice is mediated by a cis-acting upstream element close to the pancreas-specific} enhancer.

S A Keller, M P Rosenberg, T M Johnson, et al.

Genes Dev. 1990, 4:

Access the most recent version at doi:10.1101/gad.4.8.1316

References This article cites 24 articles, 13 of which can be accessed free at: http://genesdev.cshlp.org/content/4/8/1316.full.htmI\#ref-list-1

License

Email Alerting Receive free email alerts when new articles cite this article - sign up in the box at the top Service right corner of the article or click here.

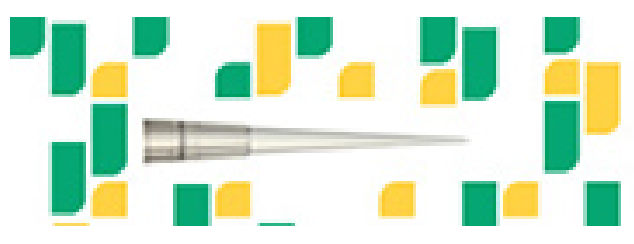

Focused on your science. 